\title{
Assessment of Oral Anticancer Medication Adherence: A Survey from a Tertiary Cancer Center
}

\author{
Balaji Ramachandiran ${ }^{1} \quad$ Biswajit Dubashi ${ }^{2} \quad$ Smita Kayal $^{3} \quad$ Vikas Menon $^{4} \quad$ K. Yuvaraj \\ C. Deepika ${ }^{5}$ Deepa Francis ${ }^{1}$ Deeksha Debbarma ${ }^{1}$ Devika S. Nair ${ }^{1}$
}

${ }^{1}$ Department of???, Jawaharlal Institute of Post Graduate Medical Education and Research, Puducherry, India

${ }^{2}$ Department of Oncology, Jawaharlal Institute of Post Graduate Medical Education and Research, Puducherry, India

${ }^{3}$ Department of Medical Oncology, Jawaharlal Institute of Post Graduate Medical Education and Research, Puducherry, India

${ }^{4}$ Department of Psychiatry, Jawaharlal Institute of Post Graduate Medical Education and Research, Puducherry, India

${ }^{5}$ Department of Preventive and Social Medicine, Jawaharlal Institute of Post Graduate Medical Education and Research, Puducherry, India

\section{South Asian J Cancer 2021;10:127-130.} Address for correspondence Biswajit Dubashi, Department of
Oncology, Jawaharlal Institute of Post Graduate Medical Education
and Research, Puducherry, India (e-mail: drbiswajitdm@gmail.com).

\section{Abstract

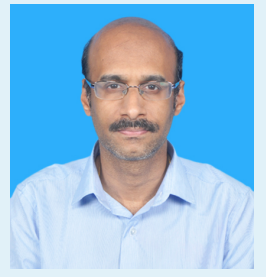 \\ Biswajit Dubashi}

Keywords

- cancer

- chemotherapy

- drug adherence
Background Adherence to oral anticancer medication is important in cancer chemotherapy, with the advent of many oral anticancer regimens to ensure adequate cytologic response. Literature on adherence to oral anticancer therapy in India is very less. Materials and Methods This is a cross sectional analytical study consisting of all fit patients $>18$ years of age taking oral anticancer therapy, with or without intravenous (IV) chemotherapy. Adherence was determined using Morisky-Green-Levine (MGL) scale, and factors affecting adherence details about cancer and treatment were obtained. All fit patients were recruited. Information was obtained using Tamil questionnaire and pro forma.

Observation Of 152 patients, only 111 patients were found to be adherent to treatment. The mean age of the study population was $49.03 \pm 13.48$ years. Only $12.5 \%$ of patients were aware of the diagnosis, treatment, and outcome. The study population consisted mainly of patients with chronic myeloid leukemia, colorectal carcinoma, breast carcinoma, and stomach carcinoma, which amounted for $78.3 \%$ of the study population. Bivariate analysis concluded that duration of treatment, adverse drug reaction (ADR), duration of oral anticancer drug intake in a month, coadministration with IV anticancer drugs, and frequency of drug intake (anticancer drug) were significant factors affecting drug adherence. Multivariate analysis of the above variables was insignificant, but ADR tended toward significance.

Conclusion Drug adherence plays a major role in treatment outcome in cancer patients. ADR was independently associated with decreased drug adherence. Key interventions which should include counseling and behavioral modifications will reduce nonadherence.
DOI https://doi.org/10.1055/s-0041-1723120 ISSN 2278-330X.

How to cite this article: Ramachandiran B, Dubashi B, Kayal S, Menon V, Yuvaraj K, Deepika C, Francis D, Debbarma D, Nair D. S. Outcomes of Palliative Radiotherapy in Metastatic Epidural Spinal Cord Compression in Lung Cancer-A Prospective Observational Study from Tata Memorial Hospital. South Asian J Cancer 2021;10(2):127-130. (c) 2021. MedIntel Services Pvt Ltd.

This is an open access article published by Thieme under the terms of the Creative Commons Attribution-NonDerivative-NonCommercial-License, permitting copying and reproduction so long as the original work is given appropriate credit. Contents may not be used for commercial purposes, or adapted, remixed, transformed or built upon. (https://creativecommons.org/licenses/by-nc-nd/4.0/)

Thieme Medical and Scientific Publishers Pvt. Ltd., A-12, 2nd Floor, Sector 2, Noida-201301 UP, India 


\section{Background}

Adherence to treatment is essential for complete cure. Many oral anticancer regimens have been approved for treatment with equivalent efficacy to parenteral regimens. However, the question of adherence arises. Suboptimal adherence is a barrier to effective use of oral anticancer drugs. ${ }^{1}$ Nonadherence also affects the patient-physician relationship and has a negative effect on the patient's views about physicians and services. ${ }^{2}$

Oncologists assume that cancer patients will take their medications as prescribed. ${ }^{3,4}$ Therefore, this study will help us understand the prevalence of nonadherence. Poor adherence leads to unfavorable outcome and decreases the 5-year eventfree survival of the patients. It will decrease the likelihood of achieving complete cytogenetic response. ${ }^{5}$ Nonadherence also leads to unwanted diagnostic and treatment procedures, causing health problems. ${ }^{2}$

\section{Aims and Objectives}

The primary objectives of the study were to determine the adherence rates of oral anticancer regimens for different types of cancer in an urban setting and to determine the various factors affecting adherence.

\section{Materials and Methods}

The study is cross-sectional analytical consisting of a single group. All fit patients, (patients who were able to fill the questionnaire on their own or able to answer the questions when asked) > 18 years of age, and on oral anticancer drugs for cancer who have taken the drug for at least 1 month, with or without concomitant intravenous (IV) anticancer drugs, were included in the study. Convenient sampling was done. All consecutive patients fulfilling inclusion criteria attending the Medical Oncology Outpatient Department clinic from June 2017 to September 2017 were taken up for the study. The basic sociodemographic details about the cancer diagnosis and the treatment were collected using a pro forma. A standardized Tamil questionnaire consisting of a set of questions to identify the factors affecting adherence was used. To determine adherence, the Morisky-Green-Levine (MGL) adherence scale ${ }^{6}$ was used.

The Institute Ethics Committee approval was obtained. The questionnaire and the MGL scale were translated into Tamil and the Tamil form was retranslated to English by another person and checked for standardization.

\section{Statistical Analysis}

The association of adherence with the categorical variable was performed by Chi-square or Fisher's exact test. The independent factors associated with adherence pattern were explored using logistic regression analysis. All statistical analysis was performed by $5 \%$ level of significance, and $p<0.05$ was considered as statistically significant. The analysis was performed by SPSS version 19 .

\section{Observation and Results}

The study included 152 patients fulfilling the inclusion criteria. It was found that $73 \%$ of the patients were adherent and $27 \%$ of the patients were nonadherent. The mean age of the study population was $49.03 \pm 13.4$ years. Approximately $52.6 \%$ of the patients were $>50$ years of age, with equal proportions of males and females, and $93.4 \%$ of the patients had a caretaker. About $30 \%$ of the patients were uneducated and $45 \%$ of the patients were unemployed. Nearly $54.6 \%$ of patients were on treatment for $<12$ months duration (median of 9 months with an interquartile range of 4-42 months) and $34.2 \%$ of patients did not take any oral supportive medications. About $71.7 \%$ of the patients took their medications themselves and $41.4 \%$ of patients experienced adverse drug reactions (ADRs). About $63.7 \%$ of patients had solid malignancies and the rest were hematological malignancies (- Table 1).

About $97.4 \%$ were aware that they had cancer, and $12.5 \%$ of patients were aware of the diagnosis, treatment, and outcome. About $61.2 \%$ received majority of the information before treatment initiation, $93.4 \%$ of the patients received majority of knowledge from physicians, and $42.8 \%$ of the patients were aware about the outcomes of nonadherence. Only $9.2 \%$ of patients stopped drugs intermittently without consulting the physicians. Almost 98\% did not use any methods to avoid forgetting to take medications. About 23\% of patients experienced difficulty in remembering to take medications on time, and $11.8 \%$ of patients considered taking medications as an inconvenience. A major proportion of patients $(67.1 \%)$ visited their physicians once in every 3 to 4 weeks. Only $16.5 \%$ of patients visited doctors besides scheduled visits, with the most common reason being pain due to illness, followed by side effects, fever, and doubts regarding drug intake in decreasing order of magnitude. About $92.8 \%$ of patients were satisfied with their physicians.

Adherence rates in gastric cancer and breast cancer were $60 \%$ and $68 \%$, respectively. Chronic myeloid leukemia (CML) and colorectal cancer had a better drug adherence rate of $75 \%$. A majority of the patients (75.6\%) who were nonadherent mentioned forgetfulness as a reason for being nonadherent followed by carelessness ( - Table 2 ).

On bivariate and multivariate analysis, we observed that patients with $<1$ year of treatment, adverse effects, taking oral anticancer drugs for $<21$ days per month, coadministered with IV anticancer drugs, and patients with more than once daily dosing had significantly poor adherence. Bivariate analysis of other variables such as age, sex, caretaker, occupation, income, hospital distance, comorbidities, type and stage of cancer, chemotherapy regimen, dose of drugs, oral supportive drugs, knowledge about disease, and treatment were insignificant. On multivariate analysis, only ADR showed a trend toward correlation with nonadherence.

\section{Discussion}

In spite of increased use of oral anticancer drugs in the recent times, the number of studies addressing the issue of 
Table 1 Distribution of study participants based on type and stage of cancer and details of oral anticancer medications intake $(n=152)$

\begin{tabular}{|c|c|}
\hline Details & $\begin{array}{l}\text { Study population } \\
(n=152)\end{array}$ \\
\hline Hematological malignancies & $56(36.8)$ \\
\hline ALL & $6(3.9)$ \\
\hline CLL & $2(1.3)$ \\
\hline CML & $47(30.9)$ \\
\hline $\mathrm{NHL}$ & $1(0.66)$ \\
\hline Solid malignancies & $96(63.2)$ \\
\hline Breast carcinoma & $25(16.4)$ \\
\hline Stomach carcinoma & $23(15.1)$ \\
\hline Colorectal carcinoma & $25(16.4)$ \\
\hline Others & $23(13.3)$ \\
\hline \multicolumn{2}{|l|}{ Stage of cancer } \\
\hline Early & $58(38.1)$ \\
\hline Locally advanced/metastatic & $92(60.5)$ \\
\hline Unknown & $2(1.3)$ \\
\hline \multicolumn{2}{|l|}{ Oral anticancer medication } \\
\hline Capecitabine & $55(36.2)$ \\
\hline Imatinib & $51(33.5)$ \\
\hline Letrozole & $14(9.2)$ \\
\hline Tamoxifen & $10(6.6)$ \\
\hline Gefitinib & $7(4.6)$ \\
\hline 6MP, MTx & $6(4)$ \\
\hline Hydroxyurea & $3(2)$ \\
\hline Sorafenib & $2(1.3)$ \\
\hline Chlorambucil & $2(1.3)$ \\
\hline Nilotinib & $1(0.7)$ \\
\hline Prednisolone & $1(0.7)$ \\
\hline \multicolumn{2}{|l|}{ Number of tablets/day } \\
\hline $1-3$ & $67(44.1)$ \\
\hline $4-6$ & $38(25)$ \\
\hline $5-8$ & $36(23.7)$ \\
\hline Unknown & $11(7.2)$ \\
\hline \multicolumn{2}{|l|}{ Frequency of administration (daily) } \\
\hline Once & $92(60.5)$ \\
\hline Twice & $58(38.2)$ \\
\hline Thrice & $2(1.3)$ \\
\hline \multicolumn{2}{|c|}{ Duration of oral anticancer drug intake in a month (days) } \\
\hline $5-14$ & $3(2)$ \\
\hline $15-21$ & $27(17.8)$ \\
\hline $22-30$ & $122(80.2)$ \\
\hline \multicolumn{2}{|c|}{ Coadministration with intravenous anticancer drugs } \\
\hline Yes & $54(35.5)$ \\
\hline No & $98(64.5)$ \\
\hline
\end{tabular}

(Continued)
Table 1 (Continued)

\begin{tabular}{|l|l|}
\hline Details & $\begin{array}{l}\text { Study population } \\
(\boldsymbol{n}=152)\end{array}$ \\
\hline \multicolumn{2}{|l|}{ Withholding of drugs by doctor } \\
\hline No & $116(76.3)$ \\
\hline Yes & $36(23.7)$ \\
\hline Reasons & $11(30.5)$ \\
\hline Low counts & $5(13.9)$ \\
\hline ADR & $3(8.3)$ \\
\hline Fever & $19(52.8)$ \\
\hline Others & \\
\hline ADR & $89(58.6)$ \\
\hline No & $63(41.4)$ \\
\hline Yes &
\end{tabular}

Abbreviations: 6MP, 6-mercaptopurine; ADR, adverse drug reactions: ALL, acute lymphoblastic leukemia; CLL, chronic lymphoid leukemia; $\mathrm{CML}$, chronic myeloid leukemia; MTx, methotrexate; NHL, nonHodgkin lymphoma.

Table 2 Reasons for nonadherence $(n=41)$

\begin{tabular}{|l|l|}
\hline Reason & Study population \\
\hline Forgetfulness & $31(75.6)$ \\
\hline Carelessness & $9(21.9)$ \\
\hline Not taking drugs when feeling better & $3(7.4)$ \\
\hline $\begin{array}{l}\text { Not taking drugs thinking they are } \\
\text { harmful to the body }\end{array}$ & $5(12.1)$ \\
\hline $\begin{array}{l}\text { More than one reason was mentioned by patients as reasons for } \\
\text { nonadherence }\end{array}$ \\
\hline
\end{tabular}

adherence is very low. The study assessed the adherence of oral anticancer medication in a tertiary cancer government hospital. We identified that $27 \%$ were nonadherent. Our study looked at adherence rates both in solid and hematological tumors. In a study by daCosta et al, which was done to assess the patient preferences and treatment adherence among, $34.8 \%$ of the women diagnosed with metastatic breast cancer were nonadherent. Patients receiving hormonal therapy reported the highest level of nonadherence. ${ }^{6}$ Forgetfulness was higher in our population when compared with a study in noncancer patients. ${ }^{7}$ In our study, $75.4 \%$ of CML patients on imatinib or hydroxyurea were adherent when compared with the study by Marin et al, which reported median adherence measured by microelectromechanical systems (MEMS) was $97.6 \%{ }^{8}$ Another study done on adherence among $\mathrm{CML}$ concluded that $32.7 \%$ of participants were highly adherent, medium adherence in $46.5 \%$, and low adherence in $20.7 \%$ of the study population. ${ }^{9}$ The possible reasons for increased nonadherence rate need to be examined in further studies. The adherence rate in CML patients as determined by the questionnaire was $74.5 \%$ which is correlating with the study done by Noens et al in which they found questionnaire-based adherence to be between $67 \%$ and $97 \%{ }^{10}$

In our study, the presence or absence of a caretaker was insignificant in bivariate analysis, but a systematic review 
done to determine adherence to oral anticancer drugs found out that patients who were living alone had poor adherence. The study also concluded that lower educational status and patients with no family history of cancer had poor adherence. ${ }^{11}$

In a study by Timmers et al, the adherence rate in patients on anticancer drugs experiencing ADR was 33\%, which was low when compared with our study. ${ }^{12}$ Veronesi et $\mathrm{al}^{13}$ and Demissie et $\mathrm{al}^{14}$ reported a nonadherence rate of $26.7 \%$ and $15 \%$, respectively, to hormonal therapy in breast cancer, which was lower than our study (32\%).

\section{Conclusion}

Drug adherence is one of the key factors for treatment failure in cancer patients. ADRs have been found as an independent variable, resulting in decreased drug adherence. Duration of treatment, coadministration with IV chemotherapeutic drugs, duration of oral anticancer drug intake in a month, and frequency of drug intake (anticancer drug) were significant factors which affect oral anticancer drug adherence. Understanding and identification of early adverse events and interventions will help decrease treatment failure. Knowledge about the disease, understanding the drug prescription, and side effects were lacking in our study group.

$$
\text { Funding }
$$

Nil.

\section{Conflict of Interest}

None declared.

\section{Acknowledgment}

This study was done and submitted to Indian Council of Medical Research (ICMR) as a part of student ICMR grant.

\section{References}

1 Urquhart J, Noncompliance: The ultimate absorption barrier. In: Prescott LF, Nimmo WS, eds. Novel Drug Delivery and its Therapeutic Application. New York: Wiley; 1989 ;127-37
2 Waterhouse DM, Calzone KA, Mele C, Brenner DE. Adherence to oral tamoxifen: a comparison of patient self-report, pill counts, and microelectronic monitoring. J Clin Oncol 1993; 11(6):1189-1197

3 Partridge AH, Avorn J, Wang PS, Winer EP. Adherence to therapy with oral antineoplastic agents. J Natl Cancer Inst 2002;94(9):652-661

4 Nilsson JL, Andersson K, Bergkvist A, Björkman I, Brismar A, Moen J. Refill adherence to repeat prescriptions of cancer drugs to ambulatory patients. Eur J Cancer Care (Engl) 2006;15(3):235-237

5 Ganesan P, Sagar TG, Dubashi B, et al. Nonadherence to imatinib adversely affects event free survival in chronic phase chronic myeloid leukemia. Am J Hematol 2011;86(6):471-474

6 daCosta DiBonaventura M, Copher R, Basurto E, Faria C, Lorenzo R. Patient preferences and treatment adherence among women diagnosed with metastatic breast cancer. Am Health Drug Benefits 2014;7(7):386-396

7 Morisky DE, Green LW, Levine DM. Concurrent and predictive validity of a self-reported measure of medication adherence. Med Care 1986;24(1):67-74

8 Marin D, Bazeos A, Mahon FX, et al. Adherence is the critical factor for achieving molecular responses in patients with chronic myeloid leukemia who achieve complete cytogenetic responses on imatinib. J Clin Oncol 2010;28(14):2381-2388

9 Geissler J, Sharf G, Bombaci F, et al. Factors influencing adherence in CML and ways to improvement: Results of a patient-driven survey of 2546 patients in 63 countries. J Cancer Res Clin Oncol 2017;143(7):1167-1176

10 Noens L, Hensen M, Kucmin-Bemelmans I, Lofgren C, Gilloteau I, Vrijens B. Measurement of adherence to BCR-ABL inhibitor therapy in chronic myeloid leukemia: current situation and future challenges. Haematologica 2014;99(3):437-447

11 Greer JA, Amoyal N, Nisotel L, et al. A systematic review of adherence to oral antineoplastic therapies. Oncologist 2016;21(3):354-376

12 Timmers L, Boons CC, Kropff F, et al. Adherence and patients' experiences with the use of oral anticancer agents. Acta Oncol 2014;53(2):259-267

13 Veronesi A, Pizzichetta MA, Ferlante MA, et al. Tamoxifen as adjuvant after surgery for breast cancer and tamoxifen or placebo as chemoprevention in healthy women: different compliance with treatment. Tumori 1998;84(3):372-375

14 Demissie S, Silliman RA, Lash TL. Adjuvant tamoxifen: predictors of use, side effects, and discontinuation in older women. J Clin Oncol 2001;19(2):322-328 